12. - A Primeira Idade do Ferro. O aparecimento do ferro. "As migraçöes" dos cavaleiros hallstattianos. O oppidum do Cayla. Civilizações itálicas. Os Vilanovianos.

Como se vê a volume é extremamente interessante pelas novidades que apresenta.

$$
E \cdot S . P \text {. }
$$

FINLEY (Moses 1.). - Les premiers temps de la Grèce: l'âge du bronze et l'époque archaïque, traduit de l'anglais par François Hartog, Paris, François Maspero, 1973, $180 \mathrm{p}$.

Como já o sugere o próprio título, a proposição central da presente obra se revela no desenvolvimento de sua estrutura narrativa. A separação e descontinuidade entre o período do bronze e a época arcaica reflete-se na divisão da obra em duas partes distintas: entre a primeira - L'âge du bronze -, englobando os capítulos 1 a 6 (Introduction, L'arrivée des grecs, Les iles: Les Cydes et Chypre, Les iles: La Crète, La Civilitation mycénienne, La fin de l'âge du bronze), e a segunda - L'époque archaïque —, englobando os capítulos 7 a 11 (Les siècles obscurs, Société et politique à l'époque archaïque, Sparte, Athènes, La Culture de la Grèce archaïque) há uma ruptura deco:rente da ruína da civilização micênica provocada pelas invasōes que por fins do séc. XIII se generalizam pelo mundo grego e Ásia Menor. Nas palavras do próprio autor:

"La société mycénienne avait été décapitée, et les gens qui restaient étaient en train, avec l'apport nouveau que représentaient les envahisseurs, de construire un nouveau type de société. ... La preuve qu'il s'agissait d'une société totalement nouvelle ne..." (pp. 85-86).

Tal ruptura, parece-nos, decorre das orientações seguidas pelo autor, as quais podem ser detetadas pela comparação entre as preocupações de ordem metodológica expostas no capítulo um (a periodização, o método analógico, os métodos cronológicos), e as proposiçōes seguidas nos demais capítulos. Assim, no $2^{\circ}$ capítulo, após criticar a identificação raça-língua-cultura o autor, para explicar a formação do complexo linguístico grego, recorre ao "mecanismo invasionista": ao discorrer sobre as evidências arqueológicas que marcam a passagem do Heládico Antigo II ao III coloca

"Normalement l'archéologie ne peut mettre un nom aux peuples ou denner un contenu aux catastrophes, mais n'est-il pas légitime, quand il s'agit de cette combinaison bien particulière de désastres, de se demander s'ils ne témoignent pas de l'arrivée, 
sur une des rives de la mer Egée, d'immigrants parlant une forme ancienne de g.ec, ..." (p. 26);

e logo adiante, ao discutir o problema da formação do dialeto dório, afirma "Quoi qu'il en soit, quelqu'un dut bien introduire le dialecte dorien dans la Grèce, ol il supplanta le "grec mycénien"..." (p. 29).

A recorrência, portanto, ao mecanismo invasionista como instância explicativa da evolução do processo cultural grego, não seiia necessária caso o autor, levando avante as preocupaçóes metodológicas do capítulo 1, aprofundasse as considerações sobre a periodização, sobretudo no que se refere à passagem da Idade do Bronze para a época arcaica, na qual predomina a utilização do ferio; em torno a essa questão se articulariam as referentes aos processos de obtenção de matéria prima (principalmente o bronze), à rede de relações culturais entre os focos de civilização orientais, o Egeu e a Europa Central e Ocidental, e ao processo de formação do complexo ling̉uístico. Para a compreensão e ressolução de tais questōes a recorrência ao método analógico, recusada pelo autor no capítulo 1, é de extrema valia, uma vez que enfatiza a preocupação em analisar aquele processo cultural em termos amplos (e, portanto, em correlação com a história mesopotâmica e egípcia), e não restritos geograficamente ao Egeu.

\section{FRANCISCO MURARI PIRES.}

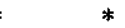

DHUODA. - Manuel pour mon fils. Introdução, texto crítico, notas por Pierre RICHE. Tradução por Bernard de Vregille e Claude Mondésert Paris. Les Éditions du Cerf. 1975. 412 pp. 100F.

Este livro é uma obra única em seu gênero. O Manual foi escrito em 842 por uma nobre dama, contempo:ânea de Lotário I e de Carlos-o-Calvo, com a intenção de servir para seu filho Guilherme que ia fazer 16 anos de idade. Afastada de Gulherme, Dhuoda redigiu e organizou para ele todo um programa de vida: deveres para com Deus e a Igreja, deveres para com seu pai e senhor, o duque Bernard da Septimânia, deveres para com o rei e os grandes, tanto na côrte como no exército. Dhuoda fala com autoridade, utilizando-se de exemplos tirados da Bíblia, da litu:gia, da sabedoria antiga e da vida da côrte, para the dar conselhos os mais justos para fazer de seu filho um jovem senhor completo que tivesse em alta conta a honra e o serviço de Deus e do soberano, ao mesmo tempo que permanecesse próximo dos pequenos e amigo da compreensão e da paz. A lição jamais foi impessoal. Dhuoda se revela como uma mulher culta e modesta, terna e corajosa. P:ocura lembrar a 